\title{
ANALISIS PERBANDINGAN PERFORMA FREERADIUS DAN USERMANAGER PADA MIKROTIK
}

\author{
Nanang Budiansyah ${ }^{1)}$ I Made Widiarta ${ }^{2)}$, Yunanri. W(3) \\ 1,2,3) Program Studi Teknik Informatika, Universitas Teknologi Sumbawa \\ email : made.widiarta@uts.ac.id
}

\begin{abstract}
Abstrak : Penelitian ini bertujuan untuk (1) menganalisa perbandingan antara freeradius dan usermanager pada Universitas Teknologi Sumbawa, dengan parameter pengukuran, waktu akses login page dan jumlah resource yang digunakan dengan sample 20 client perangkat pendukung jaringan seperti routerboard, switch, access point dan komputer server. (2) dapat memberikan masukan solusi alternatif hotspot mikrotik dalam menangani jumlah user yang banyak. Penelitian ini menggunakan metode pengembangan jaringan Network Development Life Cycle dan dibangun dengan menggunakan perangkat router board mikrotik dan 20 client pengujian. Metode pengumpulan data mengggunakan observasi, wawancara, studi pustaka dokumentasi. Hasil dari penelitian yaitu dapat mengetahui performa dari freeradius dan usermanager pada mikrotik dan memberikan solusi alternative pada mikrotik dalam menagani jumlah user aktif yang terus bertambah setiap harinya.
\end{abstract}

Kata Kunci. Jaringan, freeradius, usermanager dan NDLC.

\begin{abstract}
This study aims to (1) analyze the comparison between freeradius and usermanager at Sumbawa University of Technology, with measurement parameters, login page access time and the number of resources used with a sample of 20 client network support devices such as routerboard, switches, access points and server computers. (2) can provide input for alternative Mikrotik hotspot solutions in handling a large number of users. This research uses the Network Development Life Cycle network development method and is built using a Mikrotik router board device and 20 testing clients. Methods of data collection using observation, interviews, literature study documentation. The result of this research is to know the performance of Freeradius and Usermanager on Mikrotik and provide alternative solutions to Mikrotik in handling the increasing number of active users every day.
\end{abstract}

Keywords. Network, freeradius, usermanager and NDLC.

\section{PENDAHULUAN}

Perkembangan teknologi komunikasi menjadi kebutuhan dalam menunjang aktivitas manusia dalam bidang pendidikan. Pendidikan di Indonesia sudah berkembang pesat beberapa tahun belakangan, mulai dari tingkat sekolah dasar, sekolah menengah hingga tingkat universitas.

Universitas Teknologi Sumbawa sebagai kampus teknologi mengedepankan penggunaan teknologi informasi dalam menjalankan proses akademik dan non akademik. Tingginya kebutuhan akan teknologi informasi harus didukung dengan layanan internet yang prima.

Kondisi saat ini, di Universitas Teknologi Sumbawa untuk melakukan management jaringan menggunakan fitur hotspot yang terdapat pada MikroTik. Fitur hotspot ini memiliki fungsi Authentication, Authorization dan Accounting (AAA) dengan lisensi yang digunakan pada MikroTik yaitu lisensi level 5 yang berarti memiliki batasan user aktif maksimal 500 user.

Permasalahan yang terjadi saat ini pengguna aktif harian berkisar 400-500 user aktif, namun seiring dengan bertambahnya jumlah dosen, staf dan mahasiswa, berdampak semakin banyak user aktif yang dibutuhkan. Sehingga dengan kapasitas MikroTik saat ini yang hanya mampu mengakomodir hingga 500 user aktif dibutuhkan solusi alternatif.

Freeradius adalah sebuah layanan server yang dapat menggantikan peran usermanager atau radius pada hotspot untuk kebutuhan autentikasi user dan password berdasarkan database (Williams, 2007). Freeradius didesain spesifik untuk menangani database skala besar. Sehingga mampu menjaga kesetabilan MikroTik dalam menangani jumlah user yang banyak (www.Mikrotik.com).

Berdasarkan uraian permasalahan diatas, maka perlu diadakan penelitian untuk membandingkan performa MikroTik yang sedang digunakan di universitas teknologi Sumbawa dengan performa MikroTik yang akan peneliti usulkan, guna mengetahui performa Mikrotik sekaligus memberikan solusi terhadap permasalahan diatas. Maka dari itu peneliti mengangkat judul "Analisis perbandingan performa freeradius dan usermanager pada mikrotik".

\section{TINJAUAN PUSTAKA}

Deni Kurnia (2018) "Analisis perbandingan kinerja antara router MikroTik OS dan aplikasi Myhotspot dalam mengelola sebuah jaringan (studi kasus di SMK Cijangkar)". Dalam penelitian yang 
dilakukan Deni Kurnia menganalisis perbandingan antara dua objek yang berbeda dan melakukan analisis dari kedua objek tersebut sehingga dapat menentukan hasil dari analisa yang telah dilakukan. Hal ini tentunya selaras dengan apa yang peneliti lakukan yaitu menganalisa perbandingan antara dua objek yang berbeda.

Esabella (2016) "Perancangan Infrastruktur Jaringan Komputer Untuk Mendukung Implementasi Sistem Informasi Pada Universitas Teknologi Sumbawa". Dalam penelitian yang dilakukan Esabella menganalisis infrastruktur jaringan komputer yang telah digunakan hingga saat ini, kemudian melakukan perancangan infrastruktur jaringan komputer, setelah itu membangun dua rancangan jaringan komputer yang menghubungkan seluruh gedung pada lingkup universitas. Terdapat kesesuaian antara penelitian yang dilakukan Esabella dengan penelitian yang dilakuakan oleh penulis, kesamaan tersebut yaitu fokus penelitian yang dilakukan adalah berorientasi pada pembenahan infrastruktur. Sedangkan perbedaan dari penelitian ini adalah pada objek yang diteliti dan pada tahap penerapan atau implementasi, Esabella melakukan penelitian dan implementasi menggunakan simolator sedangkan penulis melakukan penelitian dan pengujian langsung dilapangan.

Hendra Kurniawan (2015) "Penerapan Network Development Life Cycle Dalam Perancangan Intranet Untuk Mendukung Proses Pembelajaran" Penelitian yang dilakukan juga memiliki kesamaan dengan penelitian yang dilakukan oleh penulis, kesamaan tersebut ada pada metode penelitian yang digunakan yaitu metode Network Development Life Cycle (NDLC). Sedangkan perbedaan dari penelitian ini adalah pada objek yang diteliti dan fokus penelitian yang dilakukan Hendra Kurniawan, adalah berorientasi pada cara mengimplementasikan metode NDLC.

Mulyanto dan Kudratullah (2019) "Analisis Dan Pengembangan Jaringan Komputer Dalam Mendukung Implementasi Sekolah Digital (studi kasus SD Negeri 2 Sumbawa Besar)". Dalam penelitian yang dilakukan Mulyanto dan Kudratullah menitik beratkan pada analisis dan pengembangan infrastruktur jaringan dalam penggunaan sumber daya bersama. Hal ini tentunya selaras dengan apa yang peneliti kembangkan yaitu infrastruktur jaringan.

Suryono (2017) "Rancang Bangun Server Cloud Computing Di Politeknik Negeri Bengkalis" Penelitian yang dilakukan berfokus untuk membangun sebuah server dengan memanfaatkan jaringan local area network (LAN) dan wireless local area network (WLAN). Hal ini tentunya memiliki kesamaan dengan judul yang peneliti angkat terkait dengan instalasi server. Hanya saja perbedaan dengan penelitian ini adalah perangkat dan teknologi yang digunakan serta objek penelitiannya.

\section{Dasar Teori}

Adapun dasar teori yang mendukung dalam penelitian ini sebagai berikut:

\section{Analisis}

analisis adalah sebuah kegiatan atau aktivitas yang berisi tentang menguraikan sebuah komponen, membedakan objek sesuai kriteria tertentu dan mengetahui fungsi masing-masing dalam satu keseluruhan yang terpadu. Sehingga dapat menguraikan komponen komponen pembentuknya atau menyusun komponen tersebut untuk dikaji lebih lanjut. (Harapan dkk, 2015).

\section{Perbandingan}

Perbandingan merupakan suatu metode pengkajian atau penyelidikan dengan mengadakan perbandingan diantara dua objek kajian atau lebih untuk menambah dan memperdalam pengetahuan tentang objek yang dikaji (Sjachran Basah 2009).

\section{Jaringan Komputer}

Jaringan komputer dapat diartikan sebagai kumpulan sejumlah terminal komunikasi yang terdiri dari dua komputer atau lebih yang saling terhubung. Tujuan dibangunnya jaringan komputer adalah agar informasi atau data yang dibawa pengirim (transmitter) dapat sampai kepada penerima (receiver) dengan tepat dan akurat. (Kristanto, 2003).

\section{Radius}

radius merupakan suatu protokol client-server yang dikembangkan untuk mekanisme access control yang memeriksa dan mengautentikasi pengguna berdasarkan protokol (AAA) (Muryanto 2011).

\section{METODE}

Adapun metode penelitian ini adalah sebagai berikut :

\section{Jenis Penelitian}

Jenis penelitian yang digunakan oleh penulis adalah metode penelitian kualitatif yang bersifat deskriptif yang bertujuan untuk pemaparan situasi yang diteliti dan disajikan dalam bentuk uraian naratif. Pemaparan data pada umumnya menjawab pertanyaanpertanyaan mengapa dan bagaimana suatu permasalahan yang terjadi.

\section{Metode Pengumpulan Data}

Metode pengumpulan data merupakan cara-cara yang dilakukan dalam mengumpulkan data-data yang dibutuhkan dalam suatu penelitian, dalam penelitian ini metode yang digunakan oleh penulis dalam 
proses pengumpulan data adalah sebagai berikut :

a. Observasi

Pada metode ini peneliti melakukan survei lokasi untuk mengumpulkan datadata Universitas Teknologi Sumbawa. Survei ini dilakukan untuk mencari data jaringan dan data pengguna jaringan.

b. Wawancara

Wawancara dilakukan dengan cara menanyakan langsung kepada Dir.DSTI yaitu bapak I Made Widiarta, S.Komp., tentang sistem jaringan yang ada di Universitas Teknologi Sumbawa.

c. Studi Pustaka

Pada tahap ini peneliti mempelajari konsep, teknik, maupun informasi dari berbagai sumber seperti internet, buku, jurnal, maupun artikel ilmiah lainnya yang berkaitan dengan jaringan komputer.

d. Dokumentasi

Tahap dokumentasi adalah tahapan dimana peneliti mengambil data berupa gambar atau foto dari beberapa lokasi perangkat jaringan di Universitas Teknologi Sumbawa.

\section{Metode Pengembangan Jaringan}

Adapun dari penerapan hasil metode pengembangan jaringan Network Development Life Cycle (NDLC) yang telah diterapkan sampai dengan tahap monitoring dan pada penelitian ini dibagi atas hasil pembahasan analysis, design, simulation/prototype, implementation, monitoring dan melakukan pengujian jaringan terhadap 20 komputer client untuk dijadikan sample.

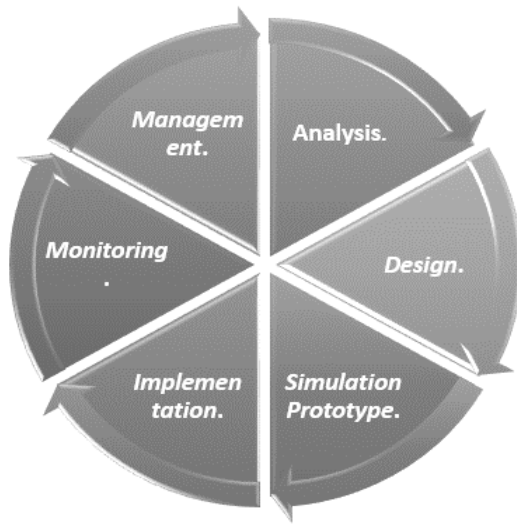

Gambar 1. Metode NDLC

Berikut adalah tahapan-tahapan dalam penelitian skripsi dengan menggunakan metode $N D L C$ sebagai metode pengembangan jaringan :

a. Analisis

Tahap awal ini dilakukan analisis kebutuhan, analisis permasalahan yang muncul, analisis keinginan pengguna, dan analisis topologi jaringan yang sudah ada saat ini. Metode yang biasa digunakan pada tahap ini diantaranya: Wawancara, Survey langsung kelapangan, Membaca manual atau blueprint dokumentasi, proyek jaringan, dokumentasi menjadi syarat mutlak setelah sistem selesai dibangun. Menelaah setiap data yang didapat dari data-data sebelumnya, maka perlu dilakukan analisis data tersebut untuk masuk ke tahap berikutnya.

b. Design

Tahap design adalah tahapan membuat gambar desain topologi jaringan interkoneksi yang akan dibangun.

Dengan gambar yang telah di desain akan memberikan gambaran seutuhnya dari kebutuhan yang ada. Desain bisa berupa desain struktur topologi, desain akses data, desain layout perkabelan, dan sebagainya yang akan memberikan gambaran jelas tentang proyek yang akan dibangun.

c. Sumulation Prototype

Pada tahap ini rancangan jaringan akan dimbuat dalam bentuk simulasi dengan bantuan tools khusus di bidang network seperti boson, packet tracert, netsim, dan sebagainya. Hal ini dimaksudkan untuk melihat kinerja awal dari jaringan yang akan dibangun dan sebagai bahan presentasi dan sharing dengan team work lainnya.

d. Implementasi

Implementasi merupakan tahapan yang sangat menentukan dari berhasil/gagalnya proyek yang akan dibangun dan ditahap inilah team work akan diuji dilapangan untuk menyelesaikan masalah teknis dan non teknis. Pada tahapan ini pekerja jaringan akan menerapkan semua yang telah direncanakan dan didesain sebelumnya.

e. Monitoring

Tahapan monitoring merupakan tahapan yang penting, agar jaringan komputer dan komunikasi dapat berjalan sesuai dengan keinginan dan tujuan awal dari user pada tahap awal analisis, maka perlu dilakukan kegiatan monitoring.

Monitoring bisa berupa melakukan pengamatan pada: Infrastruktur hardware, memperhatikan jalannya paket data di metode yang digunakan untuk mengamati kondisi jaringan dan komunikasi secara umum secara terpusat atau tersebar.

\section{HASIL DAN PEMBAHASAN}

Dari ketiga metode yang peneliti gunakan dalam pengumpulan data maka dapat diuraikan dari 
data-data yang berhasil terkumpul selama penelitian berlangsung dalam kurun waktu 3 bulan, berikut data-data tersebut:

\section{Wawancara}

Pada tahap wawancara dilakukan dengan wawancara langsung. Metode wawancara langsung dilakukan dengan memberikan pertanyaan langsung kepada Dir.DSTI Universitas Teknologi Sumbawa, berupa informasi topologi yang digunakan adalah topologi star, bandwidth sebesar $100 \mathrm{mbps}$, dan pengguna aktif harian berkisar 400500 user aktif. Dari proses wawancara yang dilakukan bahwa pihak tersebut mendukung dalam penelitian pengujian jaringan di Universitas Teknologi Sumbawa.

\section{Observasi}

Setelah melakukan observasi di Universitas Teknologi Sumbawa, pada sub bagian sistem dan teknologi dan informasi bersedia memberikan data dan informasi terkait dengan jaringan yang akan diteliti, data yang diberikan berupa skema keseluruhan jaringan yang sedang digunakan saat ini di Universitas Teknologi Sunbawa.

\section{Dokumentasi}

Hasil dari proses dokumentasi berupa foto penelitian dalam pemasangan dan pengujuan jaringan di Universitas Teknologi Sumbawa yang telah dilampirkan dilampiran.

\section{Analysis}

Hasil dari analisis kebutuhan dalam merancang jaringan yang akan diterapkan adalah sebagai berikut :

a. Analisis Kebutuhan Perangkat Keras

Adapun dari beberapa analisis kebutuhan perangkat keras yang dibutuhkan adalah sebagai berikut :

Tabel 1. Perangkat Keras

\begin{tabular}{|c|c|c|}
\hline No & Perangkat Keras & Spesifikasi \\
\hline 1 & Laptop & $\begin{array}{ll}\text { a. } & \text { Processor AMD A9-9450 } \\
& 3,00 \mathrm{GHz} \\
\text { b. } & \text { RAM } 4 \text { Gb DDR } 4 \\
\text { c. } & \text { VGA AMD Radeon HD R5 } \\
\text { d. } & \text { Harddisk } 500 \mathrm{~Gb}\end{array}$ \\
\hline 2 & Mikrotik Routerboard & $\begin{array}{ll}\text { a. } & 3011 \text { ULAS-RM } \\
\text { b. } & \text { Memory } \\
\text { c. } & \text { Boot Loader Router Boot } \\
\text { d. } & \text { Data Storage } 64 \mathrm{MB} \\
\text { e. } & 5 \text { Lan Port } \\
\text { f. } & \text { Router OS }\end{array}$ \\
\hline 3 & Kabel Lan & a. $R J-45$ \\
\hline
\end{tabular}

\section{Design}

Tahap design bagian dari proses perancangan jaringan untuk dilakukan pengujian jaringan terhadap 20 sample client. Selanjutnya untuk tahap awal yang dilakukan adalah menyesuaikan topologi yang digunakan di Universitas Teknologi Sumbawa yaitu topologi star. Didalam proses perancangan ini penulis menerapkan beberapa perancangan dari media kabel maupun media nirkabel dalam menghubungkan client kejaringan internet. Berikut uraian dari tahap perancangan dapat dilihat dibawah ini :

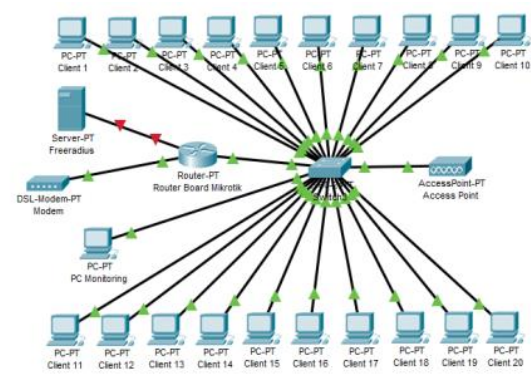

Gambar 2. Perancangan keseluruhan

\section{Simulation Prototype}

Ditahapan ini penulis akan melakukan pemilihan simulator yang akan digunakan dalam penelitian ini yaitu mengunakan Cisco Paket Tracer Versi 7.2, pada proses simulasi ini terdapat fitur-fitur yang memudahkan dalam merancang dan membangun jaringan yang memiliki berbagai kemampuan jaringan yang nyata dalam konfigurasinya, sehingga ini akan membuat simulasi jaringan sesuai dengan kenyataan dan dalam hal ini simulasi juga dapat memungkinkan untuk membangun beberapa tingkat.

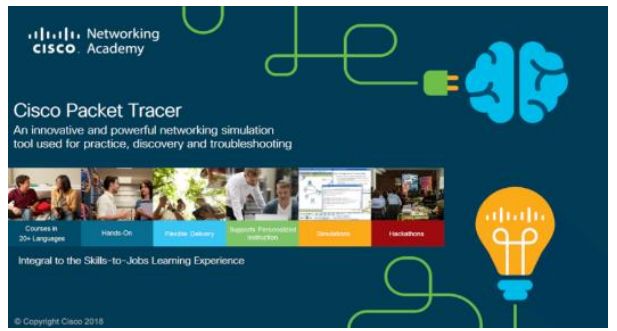

Gambar 3. Cisco Packet Tracer

Adapun simulasi freeradius server yang dilakukan pada virtual box sebagai berikut :

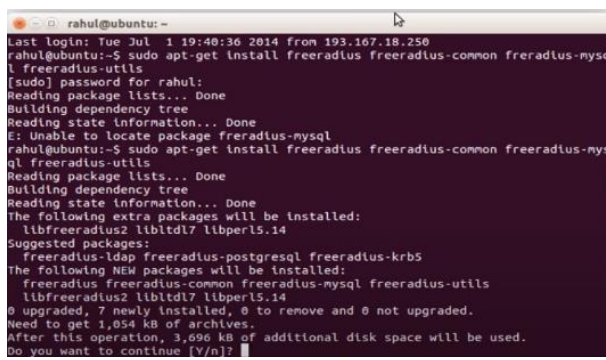

Gambar 4. Virtual Box

Pada gambar menunjukan bahwa peneliti melakukan simulasi freeradius server dengan memanfaatkan virtual machine Oracle VirtualBox. Simulasi sendiri meliputi proses install Operating system (OS) Linux Debian 9 dan proses install freeradius. Spesifikasi virtual machine yaitu storage controller Sata Port0 dengan kapasitas 8,00 $\mathrm{Gb}$ dan bases system 1024 mb, mampu melakukan proses running freeradius pada linux debian. 


\section{Implementasi}

Dalam implementasi rancang bangun jaringan menggunakan perangkat pendukung, penulis melakukan instalasi dan pengujian jaringan menggunakan aplikasi winbox untuk konfigurasi pada routerboard mikrotik. Kemudian peneliti melakukan proses install freeradius pada operating system pada linux debian 9 untuk membanding performa jaringan.

\section{a. Implementasi Konfigurasi}

Konfigurasi mikrotik terdiri dari beberapa bagaian dimulai dari login hingga konfigurasi selesai seperti dijelaskan pada masing- masing point berikut :

\section{Login mikrotik}

Sebelum melakukan konfigurasi jaringan, diperlukan aplikasi winbox yang berfungsi untuk menghubungkan routerboard mikrotik dengan komputer.

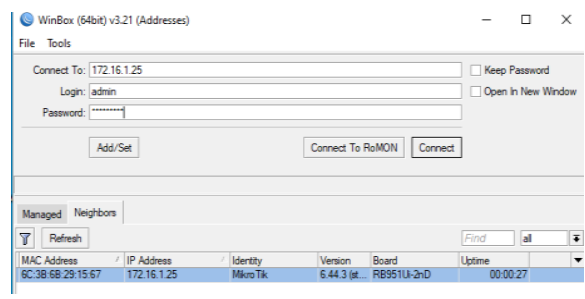

Gambar 5. Winbox

Gambar diatas dapat dijelakan bahwa peneliti dihadapkan tampilan menu login yang berisikan kolom login dan password, pada gambar diatas peneliti telah mengisi kolom login dengan admin dan password yang dirahasiakan. Selanjutnya memilih button connect pada winbox.

\section{Konfigurasi interface ether 1}

Proses selanjutnya membuat IP Address jaringan local ether 1 yang dimana IP-nya sama dengan IP internet. Routerboard mikrotik ini dapat dikonfigurasi secara grafis maupun Command Line Interface (CLI). Perintah yang digunakan untuk konfigurasin IP Address pada ether 1 adalah :IP Address add address $=192.168 .0 .102 / 24$ interface $=$ ether 1

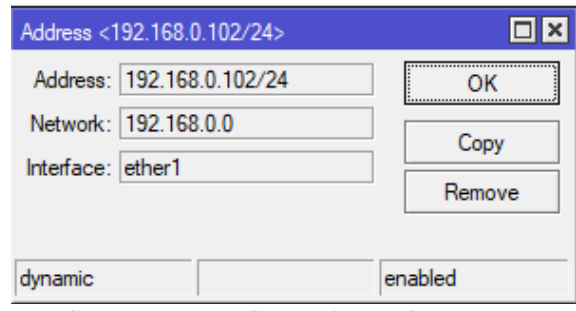

Gambar 6. Konfigurasi Interface
Gambar diatas dapat dilihat bahwa proses untuk memberikan alamat kepada port satu atau dapat disebut ether 1, dimana port satu ini akan difungsikan sebagai tempat jalur internet karena menyesuaikan dengan IP yang ada pada modem agar port lain dapat terhubung dengan internet walaupun berbeda alamat nantinya pada proses inilah yang dinamakan sebagai pemberian alamat IP agar mulai dikenali oleh modem.

\section{Monitoring}

Dalam tahapan monitoring akan dijelaskan beberapa proses yang akan dilakukan untuk memonitoring jaringan yang dibangun karena pada monitoring inilah penulis nantinya akan mengetahui keberhasilan dan kesalahan dari jaringan yang telah dibangun.

Pada tahap ini hasil monitoring akan diuraikan menjadi beberapa bagian, mulai dari hasil pengujian jaringan yang dilakukan terhadap 5 user aktif sampai dengan 20 user aktif, adapun bagian yang akan dimonitoring yaitu jumlah resource yang terpakai dan jumlah waktu yang dibutuhkan user pada mikrotik yang menggunakan usermanager dan resource yang terpakai serta jumlah waktu yang dibutuhkan user pada mikrotik yang menggunakan freeradius server.

\section{a. Grafik waktu freeradius dan usermanager}

Berikut ini merupakan grafik waktu yang dibutuhkan client dari freeradius server dan usrmanager dalam mengakses halaman login (login page).

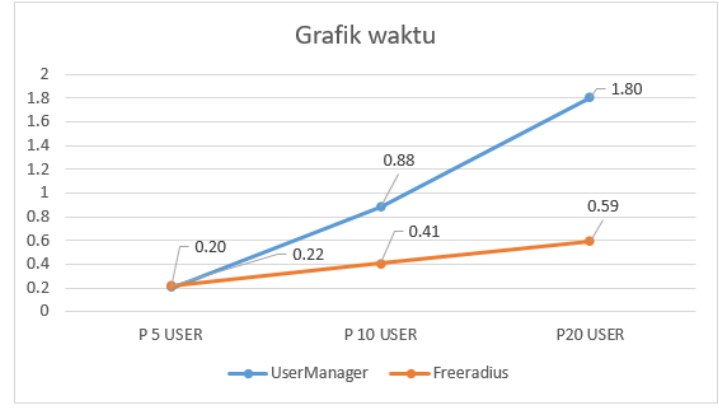

\section{Gambar 7. Grafik Waktu}

Gambar diatas dapat dijelaskan bahwa jumlah waktu yang dibutuhkan client dalam mengakses halaman login (login page) nilai yang didapat apabila menggunakan freeradius yaitu 0,22 detik untuk pengujian 5 user aktif, 0,41 detik pengujian 10 user aktif dan 0.59 detik pada pengujian 20 user aktif. Sedangkan apabila menggunakan usermanager dibutuhkan jumlah waktu dengan nilai 0.20 detik terhadap pengujian 5 user aktif, 0.88 detik pengujian 10 user aktif dan naik menjadi 1,80 detik untuk 20 user aktif. Data diatas membuktikan bahwa freeradius memiliki kecepatan yang lebih baik dibandingkan dengan 
usermanager karena client tidak membutuhkan waktu yang lama dalam mengakses login page.

\section{b. Grafik Resource CPU}

Berikut ini merupakan gambar grafik dari jumlah resource Central Processing Unit (CPU) yang terpakai pada mikrotik baik menngunakan freeradius dan usermanager untuk menjalankan fitur hotspot pada mikrotik.

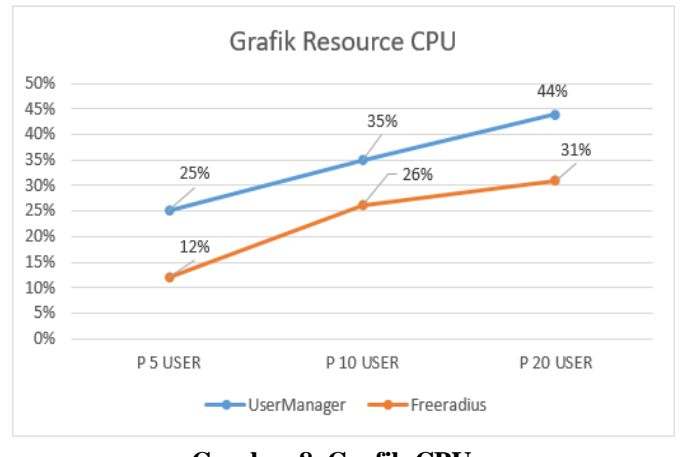

Gambar 8. Grafik CPU

Gambar diatas dapat di jelaskan bahwa jumlah resource Central Processing Unit (CPU) yang digunakan untuk menjalankan fitur hotspot pada mikrotik memanfaatkan freeradius dengan tiga tahap pengujian yaitu pengujian 5 user aktif sebesar $12 \%$, pengujian 10 user aktif $26 \%$ dan 20 user aktif $31 \%$. Sedangkan dengan memanfaatkan usermanager maka didapat nilai sebesar $25 \%$ pengujian 5 user aktif, 35\% pengujian 10 user aktif dan $44 \%$ untuk pengujian terhadap 20 user aktif. Berdasarkan hasil data diatas membuktikan bahwa performa CPU mikrotik menggunakan freeradius lebih baik dibandingkan usermanager, karena semakin sedikit jumlah pemakaian cpu maka semakin baik performa suatu router board.

\section{c.Grafik Resource Memory Mikrotik}

Berikut ini merupakan gambar grafik dari jumlah resource Memory yang terpakai pada mikrotik baik menngunakan freeradius dan usermanager untuk menjalankan fitur hotspot pada mikrotik.

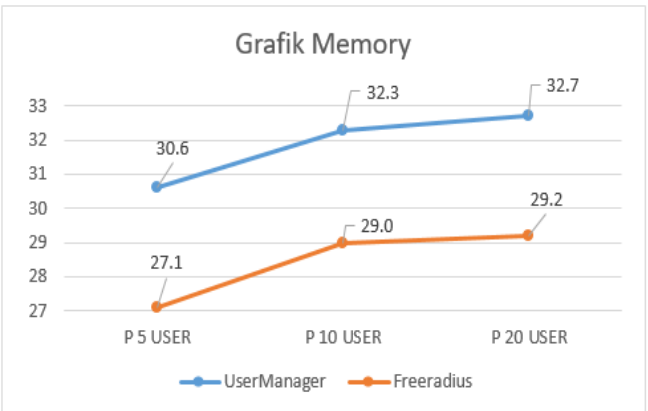

Gambar 9. Grafik Memory

Gambar diatas dapat di jelaskan bahwa jumlah resource Memory yang digunakan untuk menjalankan fitur hotspot pada mikrotik memanfaatkan freeradius dengan tiga tahap pengujian yaitu pengujian 5 user aktif sebesar 27,1 megabyte $(\mathrm{Mb})$, pengujian 10 user aktif 29,0 Mb dan 20 user aktif 29,2 Mb. Sedangkan dengan memanfaatkan usermanager maka didapat nilai sebesar 30,6 Mb pengujian 5 user aktif, 32,3 Mb pengujian 10 user aktif dan 32,7 Mb untuk pengujian terhadap 20 user aktif. Berdasarkan hasil data diatas membuktikan bahwa performa memory mikrotik menggunakan freeradius lebih baik dibandingkan usermanager, karena semakin sedikit jumlah pemakaian memory maka semakin baik performa suatu router board.

\section{KESIMPULAN DAN SARAN}

Dari penelitian yang telah dilakukan maka dapat diambil beberapa kesimpulan sebagai berikut:

1.Jaringan menggunakan router board mikrotik dengan freeradius dan usermanager untuk kebutuhan penelitian telah berhasil dibangun pada ruang lingkup laboratorium.

2.Dari hasil data analisis perbandingan jaringan menggunakan 3 tahap pengujian, freeradius server memiliki performa loading page yang lebih baik dari pada usermanager.

3.Dari data hasil analisis perbadingan jaringan menggunakan 3 tahap pengujian, menjunjukan bahwa freeradius server memiliki resource cpu load lebih rendah dibandingkan dengan usermanager.

4.Dari hasil data analisis perbandingan jaringan menggunakan 3 tahap pengujian, performa memory freeradius server lebih baik dari pada usermanager.

5.Berdasarkan hasil data pengujian jaringan yang telah dilakukan, freeradius dapat dijadikan solusi alternative dalam menggantikan peran usermanager.

Saran pada penelitian ini dibangun jaringan freeradius server dan usermanager dengan pengujian menggunakan 20 client. Diharapkan penelitian selanjutnya menggunakan jumlah client yang lebih banyak agar lebih memaksimalkan kerja dari freeradius dan usermanager.

\section{DAFTAR PUSTAKA}

Adhi, Wayan. 2019. "Sistem Operasi Server Penggunaan, Jenis dan Fungsinya". (https://dosenit.com/jaringan- 
komputer/software-jaringan/sistemoperasi-server, diakses 14 Maret 2020).

Deni Kurnia, (2018). Analisis perbandingan kinerja antara router MikroTik OS dan aplikasi Myhotspot dalam mengelola sebuah jaringan, studi kasus di SMK Cijangkar, Jurnal Tecnologia. Vol 7 No.4 Hal. 253.

Harahap, Sofyan Safri, (2013). Analisis Kritis Atas Laporan Keuangan, Raja Grafindo, Jakarta. Jurnal Sisfotek Global ISSN : 2088 - 1762 Vol. 3 No. 2 / September 2013.

Informatika, T., Bhayangkara, U., Raya, J., Perjuangan, J. R., Mulya, M., \& Utara, B. (2019). Perancangan clustering database server untuk. XVIII, 281-289.

Komarudin, (2001). Ensiklopedia Manajemen, Edisi IX, Bumi Aksara, Jakarta.

Kristanto, Andi, (2003). Jaringan Komputer, Graha Ilmu, Yogyakarta.

Kudratullah \& Yudi Mulyanto. (2019). Analisis Dan Pengembangan Infrastruktur Jaringan Komputer Dalam Mendukung Implementasi Sekolah Digital". Jinteks, 1(1), 58-67.

Kurniawan, Agus, (2014). Network Forensics Dengan Wireshark, Andi Publisher, Jakarta.

Nugroho, Kukuh, (2016). Jaringan Komputer Menggunakan Pendekatan Praktis, Mediatara, Kebumen.

O’Brien \& Marakas, (2013). Management Information Systems. Sixteenth Edition. New York: McGraw-Hill/Irwin.

Setiawan, Deris, (2009). Fundamental Internetworking Development \& Design Life Cycle, UNSRI,Palembang.
Setiawan, Guntur, (2004). Implementasi Dalam Birokrasi Pembangunan, Balai Pustaka, Jakarta.

Sofana, Iwan, 2013, Teori dan Modal Praktikum Jaringan Komputer, Indonesia : Modula, Bandung.

Sugeng, Winarno. (2010). Jaringan Komputer dengan TCP/IP. Bandung: Penerbit Informatika.

Susanto, Husaini (2017) "Pengembangan Perancangan Jaringan Local Area Network (LAN) Di Rsia Anugrah Medical Centre Metro, Universitas Islam Negeri Raden Intan Lampung, Bandar Lampung.

Usman, Nurdin, 2002, Konteks Implementasi Berbasis Kurikulum, PT.Raja Grafindo Persada, Jakarta.

Wijaya, Hendra, 2001, Virtual Local Area Network (VLAN), Bandung.

Yudianto, M.Jafar Noor, 2007, Jaringan Komputer dan pengertiannya, Www.ilmukomputer.com, Semarang, Diakses Pada 05 Januari 2019. 